doi: $10.18282 /$ jsd.v7.i1.165

\title{
REVIEW
}

\section{Fiddler's neck: Cultural influences modify clinical presentation influences}

\author{
Sundeep Chowdhry, Sameeksha Chand, Paschal D'Souza*
}

ESIPGIMSR, Basaidarapur, New Delhi, India

\begin{abstract}
Fiddler's neck which is also referred to as a "violin hickey" is a benign dermatologic occupational disease associated with the use of certain instruments like the violin, viola, cello etc. It is believed to be a type of allergic contact dermatitis, manifesting as an acute or chronic eczematous lesion typically at the submandibular and/or supraclavicular region on the side of neck. It can present as erythema, oedema and/or vesicles in the acute stage and as scaling, lichenification, hyperpigmentation and scarring in the chronic stage. Acne mechanica has also been considered by some authors as a presentation of fiddler's neck. Occasionally, there may be associated swelling redness or a cystic lesion that makes it difficult to differentiate from lymphedema or a salivary gland tumor. PubMed search for articles about this entity resulting in instrument-induced dermatitis yielded few results of this forgotten entity which mimics a love bite (love hickey). For diagnosis, history of the usage of a string instrument which is held between the shoulder and neck, local physical examination and a positive patch test are pre-requisites. Management of fiddler's neck includes application of topical mild steroid, emollient, proper instrument handling, neck padding, changing the material and polish of the instrument, and/or reducing the amount of playing time. Surgical intervention is usually not advisable unless cystic or tumorous lesions are the manifesting feature. The authors intend to revisit this entity and report an improvised modality that is being used by these instrumentalists in India which may help in prevention of this condition.
\end{abstract}

Keywords: Fiddler's neck; violin hickey; instrument induced dermatitis; allergic contact dermatitis; acne mechanica

Citation: Chowdhry S, Chand S, D’Souza P. Fiddler's neck: Cultural influences modify clinical presentation influences. J Surg Dermatol 2022; 7(1): 165; http://dx.doi.org/10.18282/jsd.v7.i1.165.

*Correspondence to: Paschal D’Souza, Clinica ESIPGIMSR, Basaidarapur, New Delhi, India; paschaldsouza@yahoo.com

Received: $7^{\text {th }}$ September 2021; Accepted: $8^{\text {th }}$ October 2021; Published Online: $30^{\text {th }}$ October 2021

\section{Introduction}

The use of various musical instruments may be associated with certain skin conditions like contact dermatitis of the hands and lips, callosities, cellist's chest, guitar nipple and Garrod's pads. Musicians can develop skin lesions associated with the type, size, positioning and duration of the usage of their instruments ${ }^{[1-8]}$. Fiddler's neck is a dermatologic entity associated with the use of instruments like the violin, viola and cello ${ }^{[6,7]}$. It usually manifests as a red mark which subsequently heals with hyperpigmentation or develops into an eczematous lesion in the submandibular and/or the supraclavicular region. The submandibular form is more commonly seen and it usually develops under the angle of the mandible where the instrument comes in contact with the chin while the supraclavicular form is usually seen on the upper chest ${ }^{[9]}$. At times, there can be associated intense oedema and thus it may be difficult to differentiate from lymphadenopathy, malignancy, or pathology of the salivary glands ${ }^{[8-11]}$. Fiddler's neck marks function as an "identifying sign" of a violinist in public view without seeing his/her instrument. This sign was even considered to be an

Copyright (C) 2022 Chowdhry S, et al. This is an Open Access article distributed under the terms of the Creative Commons Attribution-Non Commercial 4.0 International License (http://creativecommons.org/licenses/by-nc/4.0/), permitting all non-commercial use, distribution, and reproduction in any medium, provided the original work is properly cited. 
indicator of the violinst's skill, "battle scars" or "a badge of honour won" from constant practice and performances by some people on the one hand, but on the other hand, many friends giggle, family members gape and strangers stare at the marks and misconstrue them with the mimicker of love bites (love hickey).

It is important to recognize this benign cutaneous condition so as to avoid unnecessary investigations and intervention. On review of literature regarding aetiopathogenesis of this entity, it is essential to highlight a novel modality being used by violin playing instrumentalists in certain countries like India which may be useful in preventing the development of this condition amongst those musicians/instrument players who encounter this skin problem.

\section{Literature review}

We conducted a PubMed search using the key words: fiddler's neck, violin, viola, cello, musical instruments, hickey and contact dermatitis.

\section{Discussion}

Fiddler's neck was first described by Peachey and Matthews in 1978 while analysing violin and viola students in England ${ }^{[12]}$. Gambichler et al. reported the incidence of fiddler's neck to be $14.7 \%$ while Rimmer and Spielvogel observed this condition to be present in all 9 violinists and violists they studied ${ }^{[6,13]}$. Knierim et al. have considered fiddler's neck as a variant of acne mechanica ${ }^{[14,15]}$. Viola players are more susceptible to fiddler's neck in comparison to violin players because viola is larger and heavier in comparison to violin.

The submandibular location is due to mechanical pressure and shearing forces acting on the skin. Predisposing factors include prolonged duration of contact, poor hygiene, excessive perspiration and poor technique of instrument placement ${ }^{[7,12,14,16]}$. It has been hypothesized that the instruments which are bigger in size like the violin have a greater tendency to cause this pathology in comparison to smaller instruments ${ }^{[12,16]}$. As this condition is provoked by physical forces of pressure and shear, local erythema, hyperpigmentation and lichenification are more commonly seen than an eczematous lesion ${ }^{[8,12]}$. Occasionally, however, edema, inflammatory papules, pustules and scaling may develop resulting in consequent scarring ${ }^{[7,8,12]}$. Histology of lesion commonly shows hyperkeratosis, acanthosis and follicular plugging ${ }^{[12]}$. Other features include a foreignbody reaction, abscess formation, cyst and granuloma formation ${ }^{[16,17]}$. Histology is similar to that of contact dermatitis showing acanthosis, spongiosis, dilated superficial blood vessels and inflammatory infiltrate with lymphocytes and eosinophils ${ }^{[16]}$.

Abscess and cyst formation is usually associated with acne mechanica ${ }^{[14,16,17]}$. Even though submandibular fiddler's neck is a benign condition, there may be occasional pain and secondary infection ${ }^{[7,16,17]}$. The supraclavicular lesion in such cases is a type of allergic contact dermatitis (ACD) to the metal brackets used to attach the chin rest to the base of the violin or viola or the polish resin coated on the wooden body of the instrument. Players allergic to ebony and rosewood are susceptible for developing Type 1 hypersensitivity after coming in contact with the body of the musical instruments. Other materials causing allergic reaction include nickel, exotic woods, cane reed or resin ${ }^{[7,9}$, ${ }^{16,17]}$. If the chin rest screws are the source of allergy then they can be replaced by hypoallergenic titanium screws. Clinically, it presents as a pruritic, eczematous, scaly plaque with or without vesicles. There may be single or multiple lesions, depending on the number of metal brackets attached to the instrument. Hypertrophic scars or keloids may also occur in rare cases ${ }^{[7,11]}$.

Diagnosis is mainly clinical and where a high suspicion of this entity is kept in mind, a detailed history regarding the type of instrument, duration of playing the instrument and positioning of the instrument must be elicited to corroborate with the clinical features. A patch test can be performed to determine allergy to metals, varnish, resins and exotic woods. Rarely, a biopsy may be needed to exclude other skin diseases ${ }^{[10]}$.

Hot weather, tiredness, playing emotional music and playing in smaller groups are reported to exacerbate fiddler's neck as individual stress is higher. The differential diagnoses of fiddler's neck include branchial cleft cyst, diseases of salivary glands including parotid gland like sialolithiasis and adenolymphoma, lichen planus, contact dermatitis, herpes siplex, insect bites and stings ${ }^{[16,18]}$.

The management of fiddler's neck includes preventive strategies and symptomatic management of lesions. Instructions must be provided regarding proper positioning of the instrument as certain position like "drooping" can cause this condition ${ }^{[8]}$. In addition, equipping the instrument with appropriate chin and shoulder rests which are hypoallergic or non-allergic in nature is most desirable. Also, if possible, it is recommended to reduce contact with the instrument ${ }^{[7,8,9,11,16]}$. If the underlying predisposing factors are corrected, the lesions usually abate on their own and often do not occur in the first place themselves ${ }^{[7,8]}$.

Surgical intervention may rarely be required in cases where a cyst has developed. It is also advised in branchial 
cleft cyst, diseases of salivary glands including parotid gland like sialolithiasis and adenolymphoma. Compared with submandibular fiddler's neck which is caused by mechanical pressure and shear stress, supraclavicular fiddler's neck is usually caused by contact dermatitis. The latter can be treated with application of topical steroid creams and emollients.

We evaluated four patients in our outpatient department who play the violin. The average duration for which they have been playing the instrument is 15 years. The average time for which they practice is 3-4 hours per day. None of our patients knew about this entity and never experienced it practically either. A common point of observation amongst all these violinists was the use of a plastic "guard" (Figure 1) that they always affix at the end of their instruments (violin), at the site that comes in contact with their skin in the neck and upper shoulder region (Figure 2). The use of this guard is primarily to increase the thickness of that end of the instrument so that strain on the neck due to excessive tilting is reduced. A second advantage offered by this temporary fixture is that the surface of the guard is designed so as to enhance the grip of the neck on the violin body which prevents the instrument to slip under the chin due to sweat. This is especially important in a tropical country like India where there is increased sweating due to the hot and humid climate and violinists often have to perform in stage shows which are mostly in open setups. Jue et al. recommended the use of a "strad pad" to absorb perspiration and to cushion the skin from friction ${ }^{[7]}$. Finally, this plastic guard also helps to prevent damage to the polish and shine of the instrument which is lessened due to the sweat and friction over a period of time. The use of such a device may be offering an additional benefit by acting as a form of barrier between the skin and the probable potential allergens present in the material of instruments. Furthermore, it might be acting as a cushion to prevent friction between the skin and the instrument thereby reducing the impact of the shearing forces on the skin.

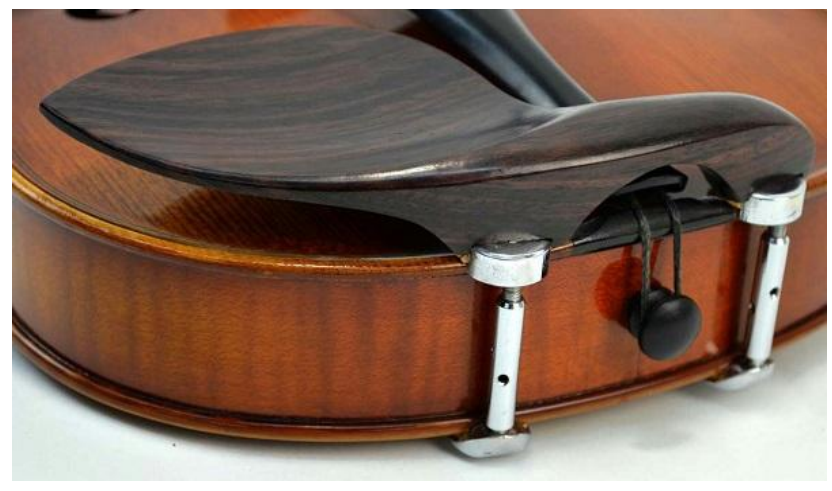

Figure 1. Plastic guard

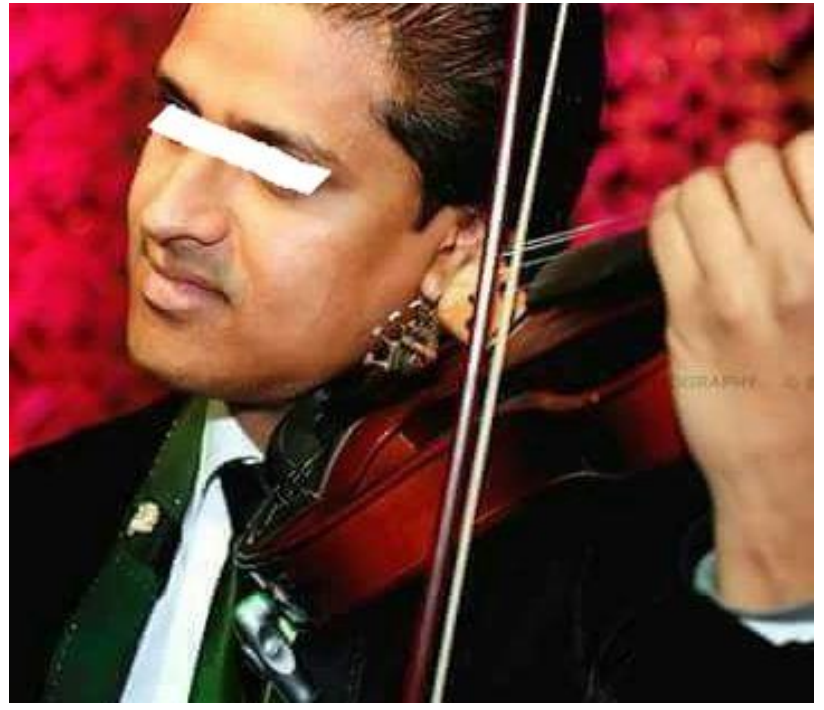

Figure 2. Violinist using plastic guard

\section{Conclusion}

Fiddler's neck or Violin hickey is a type of allergic contact dermatitis commonly seen in instrumentalists using the violin, viola and cello. Sweating, friction, pressure, type of instrument material, prolonged duration of contact and improper positioning of the playing instrument may contribute in the development of this condition. We strongly recommend the routine usage of "strad pads" or "guards" when playing instruments like the violin, viola, cello etc. during practice and otherwise. This addendum (plastic guard) reduces the physical exertion by preventing neck strain due to excessive bending unilaterally, improves the grip of the neck on the instrument, avoids slipping of one end of the instrument in sweaty conditions, maintains the shine of the instrument and most importantly, prevents the development of the fiddler's neck.

The "plastic guard" or any other soft cushion grips on one end of these musical instruments will virtually eliminate the occurrence of fiddler's neck in those musicians who play such instruments either as a hobby or do so professionally.

\section{Conflicts of interest}

The authors declare no potential conflict of interest with respect to the research, authorship, and/or publication of this article.

\section{References}

1 Lombardi C, Bottello M, Caruso A, Gargioni S, Passalacqua G. Allergy and skin diseases in musicians. Eur Ann Allergy 
Clin Immunol 2003; 35(2): 52-55.

2 Bork K. Stigmas, symptoms and diseases of the skin in musicians. Hautarzt 1993; 44(9): 574-580.

3 Crépy MN. Skin diseases in musicians. Eur J Dermatol 2015; 25(5): 375-383. doi: 10.1684/ejd.2015.2559.

4 Cohen PR. Harpist's finger: Case report of a traumainduced blister in a beginner harpist and review of string instrument-associated skin problems in musicians. Cutis 2008; 82(5): 329-334.

5 Lieberman HD, Fogelman JP, Ramsay DL, Cohen DE. Allergic contact dermatitis to propolis in a violin maker. $\mathrm{J}$ Am Acad Dermatol 2002; 46(2 Suppl Case Reports): S30 31.

6 Gambichler T, Uzun A, Boms S, Altmeyer P, Altenmüller E. Skin conditions in instrumental musicians: A self-reported survey. Contact Dermatitis 2008; 58(4): 217-222.

7 Jue MS, Kim YS, Ro YS. Fiddler's neck accompanied by allergic contact dermatitis to nickel in a viola player. Ann Dermatolo 2010; 22(1): 88-90. doi: 10.5021/ad.2010.22.1. 88.

8 Stern J. The edema of fiddler's neck. J Am Acad Dermatol 1979; 1(6): 538-540.

9 Caero JE, Cohen PR. Fiddler's neck: Chin rest associated irritant contact dermatitis and allergic contact dermatitis in a violin player. Dermatol Online J 2012; 18(9): 10.
10 Myint CW, Rutt AL, Sataloff RT. Fiddler's neck: A review. Ear Nose Throat J 2017 Feb; 96(2): 76-79.

11 Yeo DK, Pham TP, Baker J, Porters SA. Specific orofacial problems experienced by musicians. Aust Dent J 2002; 47(1): 2-11. doi: 10.1111/j.1834-7819.2002.tb00296.x.

12 Peachey RD, Matthews CN. Fiddler's neck. Br J Dermatol 1978; 98(6): 669-674. doi: 10.1111/j.1365-2133.1978.tb03 586.x.

13 Rímmer S, Spielvogel RL. Dermatologic problems of musicians. J Am Acad Dermatol 1990; 22(4): 657-663.

14 Knierim C, Goertz W, Reifenberger J, et al. Fiddler's neck (German). Hautartz 2013; 64(10): 724-726. doi: 10.1007/s0 0105-013-2647-5.

15 Crěpy MN. Skin diseases in musicians. Eur J Dermatol 2015; 25(5): 375-383. doi: 10.1684/ejd.2015.2559.

16 Moreno JC. Gata IM, García-Bravo B, Camacho FM. Fiddler's neck. Am J Contact Dermat 1997; 8(1): 39-42. doi: 10.1016/S1046-199X(97)90035-X.

17 Gambichler T, Boms S, Freitag M. Contact dermatitis and other skin conditions in instrumental musicians. BMC Dermatol 2004; 4: 3. doi: 10.1186/1471-5945-4-3.

18 Tennstedt D, Cromphaut P, Dooms-Goossens A, Lachapelle JM. Dermatoses of the neck affecting violin and viola players (fiddler's neck and contact dermatitis). Derm Beruf Umwelt 1979; 27(6): 165-169. 